\title{
Study on Combustion Characteristics of Pulverized Coal Based on Instantaneous Two-dimensional Measurement
}

\author{
Xinyuan Pan ${ }^{a}$, Shixing Ding ${ }^{b}$, Shi Liuc, Zhaoyu Liu ${ }^{d}$, and Baoming Sun ${ }^{e}$ \\ North China Electric Power University, Beijing,102206, China. \\ a18810788502@163.com, ${ }^{b}$ ncepudsx@163.com, ${ }^{c}$ Liushi@126.com
}

Keywords: pulverized coal combustion; $\mathrm{OH}$ distribution; simultaneous measurement; acidification treatment.

\begin{abstract}
The purpose of this paper is to compare the releasing characteristics of the flame intermediate $\mathrm{OH}$ when the pulverized coal from Zhundong region and the acidified treated pulverized coal are completely burned at constant temperature. Since the content of the $\mathrm{H}$ in the complete combustion intermediate product $\mathrm{OH}$ is corresponding to the content of the $\mathrm{H}$ element in the pulverized coal, and then it can be used to compare the changes of the $\mathrm{H}$ content in Pulverized Coal after pickling. An open-type burner is fabricated to apply optical measurement techniques. In this paper, simultaneous measurement of $\mathrm{OH}$-planar laser-induced fluorescence (PLIF) is performed and the entire main combustion area is examined. It is found that the content of $\mathrm{OH}$ in the acidified treated pulverized coal is generally lower (compared with the raw coal), which is consistent with the results of the pulverized coal ultimate analysis. Meanwhile, it is found that the burning range of the whole pickled coal flame becomes smaller and that the peak value of the coal powder after pickling is slightly delayed.
\end{abstract}

\section{Introduction}

Coal is an important and promising energy resource for electricity supply because its reserve is far more abundant than those of fossil fuels, especially in China[1, 2]. An amount of coal storage was found in the zhundong region (in the east of Junggar Basin) of China. According to China's annual production of coal, a zhundong coal field is enough for the whole country to use for a hundred year[3], so the study of the zhundong coal is very important. The zhundong coal's alkali metal content is high, especially the content of $\mathrm{Na}$ is relatively high, which can cause serious pollution[4]. Sodium salt is volatile substance, which volatiles at high temperatures and is easy to condense in the heating surface to form sintered or cohesive ash deposition, but pickling treatment can remove most of the alkali metal elements such as sodium[5-7]. In this study, planar laser-induced fluorescence[8, 9] is combined with a laboratory-scale pulverized-coal combustion burner. Spatial relationship of the combustion reaction zone and the relative content of the mid products $\mathrm{OH}$ of the flame is detected, 
and it is investigated by simultaneous measurement of OH-PLIF[10, 11]. The intensity profiles of OH-PLIF are analysed by statistical methods.

\section{Experiment Apparatus and Arrangements}

\subsection{Pulverized-coal combustion burner}

The turbulence pulverized-coal combustion burner is fabricated as an open-type apparatus to apply various optical measurement techniques. The burner and the supplying system are illustrated in Fig.1. The burner is a tapered burner and the inlet gas of the burner is the premixed methane with air, and the outlet is a round-shaped combustion plate made of high-temperature iron-nickel alloy. The diameter of the combustion plate is $60 \mu \mathrm{m}$. The mixed gas can pass smoothly through the combustion plate. The external part is made of closed ring refractory material, so the mixed gas in the upper part of the burner achieves a buffering effect to avoid blowing pulverized coal directly. The main air for combustion and the combustion-supporting methane is supplied from a compressor and the flow rate is regulated by a screw controller. Coal particles with a diameter of $75 \mu \mathrm{m}$ are placed on the combustion plate, controlling the flow rate of the mixed gas to make the pulverized coal in a semi-suspended state so that the gas is in full contact with the gas. The coal used in this experiment is zhundong coal.

The acidified pulverized coal is treated on the basis of the coal. Table 1 shows the ultimate analysis of two pulverized-coal. In this study, the mixture of methane and air passes through the combustion plate. In one aspect, it achieves the effect of combustion-supporting, because the mass of coal is small and flame stabilization is impossible for pure pulverized-coal flame. In another aspect, it ensures the pulverized coal in sufficient contact with the pulverized coal particles to ensure full combustion. The exhausted gas is released into the atmosphere by a ventilator after cooling.

The diameter of Zhundong pulverized coal is $75 \mu \mathrm{m}-20 \mu \mathrm{m}$. The weight of coal samples used is $2.000 \mathrm{~g}( \pm 0.0010 \mathrm{~g})$, and it was put into triangular conical flask. Next, $150 \mathrm{~mL}$ ultrapure water was added with the rotor and then the conical flask was sealed with a sealing film. The mixture was stirred at $20{ }^{\circ} \mathrm{C}$ for 12 hours. The mixture was filtered through a solvent filter and the residue was washed. The residue was transferred to $1 \mathrm{~mol} / \mathrm{L}$ of a $150 \mathrm{~mL} \mathrm{HCl}$ solution for 12 hours and then filtered, washed and dried.

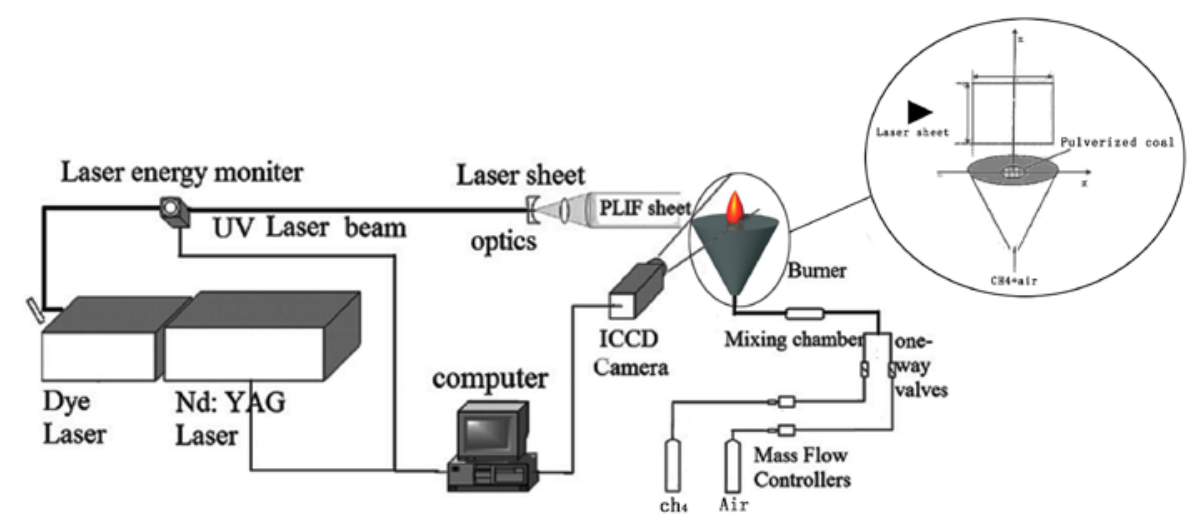

Figure. 1 


\subsection{Optical measurement system}

In the study, PLIF is applied to pulverized-coal flame, and the detailed combustion characteristic of devolatilization is examined. Furthermore, the spatial relationship of the combustion reaction zone is investigated. The simultaneous measurement system for OH-PLIF is shown in Fig.1.

Table 1 Ultimate analysis

\begin{tabular}{ccccc}
\hline Coal sample & Carbon & Hydrogen & Nitrogen & Total sulfur \\
\hline raw coal & 66.20 & 3.67 & 0.64 & 0.62 \\
\hline Acidified coal & 65.62 & 3.27 & 1.03 & 0.45 \\
\hline
\end{tabular}

A ND: YAG pulse laser (spectra-physics) is used as the light source of the laser sheet. For the OH-PLIF, the P1(8) absorption line of the $(1,0)$ band is excited using a wavelength-tunable laser () pumped by the third-harmonic wave of the ND: YAG pulse laser. Laser-induced OH fluorescence, on the one hand, is passed through an optical hand-pass interfere filter with a transmission peak wavelength of $320 \mathrm{~nm}$ and a half-value width of $20 \mathrm{~nm}$ and is captured by a CCD camera () coupled with an image intensifier. TTL signal generated by two pulse delay generators are used for timing control of the ND: YAG pulse laser and image capture of the OH-PLIF. In the measurement of OH-PLIF, the Rayleigh scattering image of air is measured, and the correction of laser intensity distribution along the axis direction is performed.

\subsection{Experimental methods and conditions}

In the experiment, first of all, the gas flame, where air and methane are supplied to the combustion plate. After 12 minutes, the temperature of the combustion plate was measured with a thermocouple about 800 degrees centigrade. Because the mass of the pulverized coal is less, the combustion time is short, and the combustion is completed within 12s during the test, so the temperature on the combustion plate can be regarded as a constant value. Table 2 shows the experimental conditions. Open the laser in advance, in this measurement, the excited of OH-PLIF fluorescence was obtained using a $10 \mathrm{HZ}$ ND: YAG laser with power of $250 \mathrm{~mJ}$ per pulse and a pulse time of $10 \mathrm{~ns}$.LIF signals of $\mathrm{OH}$ emission at wavelength around $283.286 \mathrm{~nm}$ were detected by intensified relay optics and a CCD camera equipped with a UV lens and an OH filter. 120 images are used for each specified case, with all OH-PLIF images corrected by subtracting the background images from the experimental images data, along with intensity correction through the energy monitor. When the mixture gas reaches 800 degrees centigrade in 12 minutes, the pulverized coal is arranged on the combustion plate, and then the $\mathrm{OH}$ in the pulverized coal is measured. In this study, the pulverized-coal flame is of the open type, and it is considered that the excess air coefficient is not important, because not only the mixed gas contains air, but also the combustion by entrainment of ambient air occurs. The airflow rate is determined to avoid the deposition of the coal particles on the combustion plate. The choosed methane flow rate is the minimum amount to form a stable flame. Fig. 1 shows the measurement and data processing area, where the axial and radial distances are shown in zone $\mathrm{z}$ and zone $\mathrm{x}$ respectively.

Table 2 Experimental conditions

\begin{tabular}{cc}
\hline Quality of pulverized coal & $1.5 \mathrm{~g}$ \\
\hline Air flow rate & $2.17 \times 10^{-5} \mathrm{~m} 3 / \mathrm{s}$ \\
\hline CH4 flow rate & $2.44 \times 10^{-4} \mathrm{~m} 3 / \mathrm{s}$ \\
\hline Thermal input of $\mathrm{CH} 4$ & $4.39 \mathrm{kw}$ \\
\hline
\end{tabular}




\section{Results and Discussion}

\subsection{Total amount of $\mathrm{OH}$ in combustion process}

In order to compare the total amount of $\mathrm{OH}$ in the acidification treated coal and raw coal in the entire combustion process, the picture of the entire combustion process (12s) was superimposed. The total distribution of $\mathrm{OH}$ in the whole process are shown in Fig.2, In addition, the intensity profiles on the horizon $(\mathrm{z}=0,20,40,60)$ are shown in Fig.3.

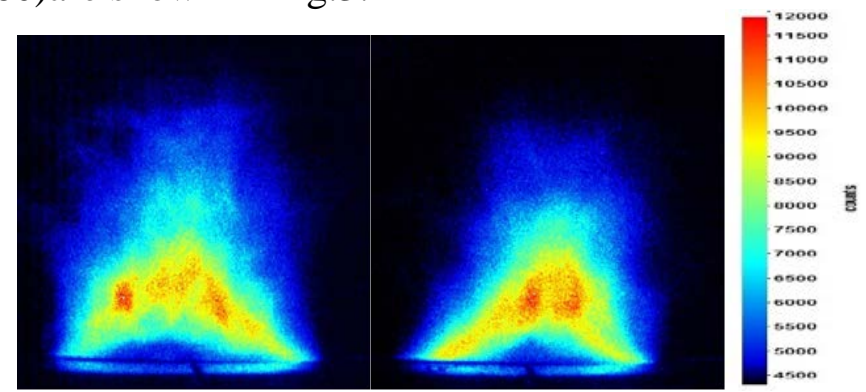

Fig.2 $\mathrm{OH}$ total distribution

From the $\mathrm{OH}$ of Fig.2, it can be seen that the distribution of the $\mathrm{OH}$ intensity of the pulverized coal after being pickled is weaker than that of the raw coal, and the whole $\mathrm{OH}$ range is smaller than that of the raw coal. That is to say, the combustion range of the pulverized coal after acidification will be smaller, which is beneficial to reduce the slagging on the heating surface [12]. Because it is complete combustion, the $\mathrm{H}$ element in $\mathrm{OH}$ comes from the pulverized coal completely, in other words, after pickling treatment of pulverized coal, the content of $\mathrm{H}$ element will be reduced, which is consistent with the ultimate analysis of the two pulverized coal. It also reflects that using instantaneous measurement PLIF to monitor is effective.

From the distribution of $\mathrm{OH}$ at different heights of Fig.3, the area covered by the distribution line and the time axis is the total content of $\mathrm{OH}$ at this height. When $\mathrm{Z}=0 \mathrm{~mm}$ and $\mathrm{Z}=20 \mathrm{~mm}$, the total content of $\mathrm{OH}$ on the horizontal axis is approximately equal, and when $\mathrm{Z}=40 \mathrm{~mm}$ and $\mathrm{Z}=60 \mathrm{~mm}$, the total distribution of $\mathrm{OH}$ on the horizontal axis is obviously different. The $\mathrm{OH}$ distribution range of acidified coal powder is smaller than that of raw coal, while the $\mathrm{OH}$ value is nearly equal. That is to say, the total amount of $\mathrm{OH}$ in the raw coal is more than that of the coal which has been treated by acidification, and further explained in terms of content that the content of $\mathrm{H}$ element in the pulverized coal is reduced.

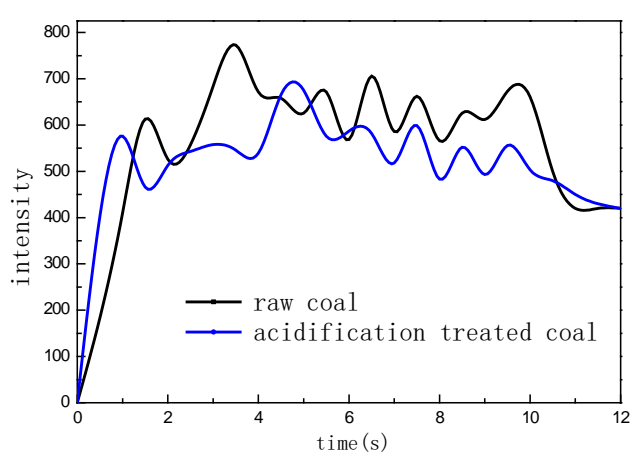

Fig.3 The maximum intensity of the process 


\subsection{Maximum intensity of $\mathrm{OH}$ process}

From Fig.2 and Fig.3 we know that the amount of total $\mathrm{OH}$ in the acidified coal is reduced. In order to compare the precipitation strength of $\mathrm{OH}$ in the whole combustion process, the maximum value of $\mathrm{OH}$ in the whole combustion process is shown in Fig. 4. From Fig.4, on the whole, the maximum value of $\mathrm{OH}$ in the whole process, that is, the most intense moment of combustion, the acidification of the coal will be delayed. However, the time for the end of burning of the raw powder is slightly ahead of schedule, which may be related to the decrease of alkali metal after treatd and the catalytic action weakened [13]. At the same time, the maximum intensity of $\mathrm{OH}$ releasing in combustion process is weaker, which is corresponding to the content of $\mathrm{OH}$

$\mathrm{Z}=0 \mathrm{~mm}$
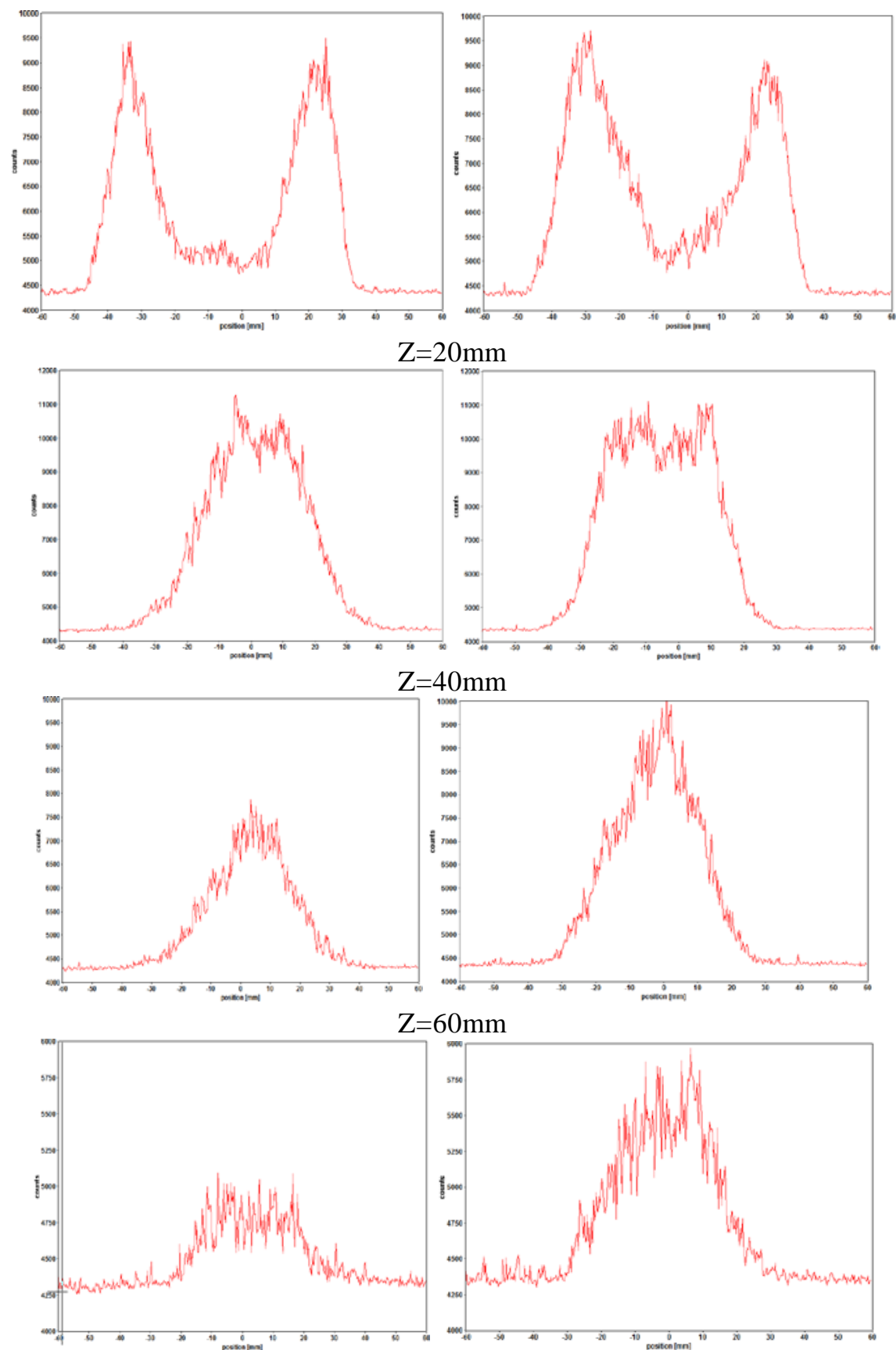

Fig.4 The distribution of $\mathrm{OH}$ at different heights 


\section{Conclusion}

Planar laser-induced fluorescence (PLIF) was applied to a laboratory-scale pulverized-coal combustion burner, and the spatial relationship of the $\mathrm{OH}$ distribution was investigated by simultaneous measurement of OH-PLIF. To investigated the structure in detail, statistical analysis was performed using the intensity profile of OH-PLIF. The main results obtained in this study Can be summarized as follows.

(1) It is found that the total content of $\mathrm{OH}$ in the whole process of pulverized coal after pickling is reduced, that is to say, the content of $\mathrm{H}$ in the treated pulverized coal will decrease, which is consistent with the result of elemental analysis.

(2) The coal powder treated by acidification has little change in the flame height, but it becomes smaller in width, that is to say, the flame is thinner than the raw coal, thus further reducing the slagging problem of the boiler heating surface, and making better use of the zhundong coal.

(3) The most intense moment of coal combustion after acidification is delayed, and the peak value of each time is smaller than that of raw coal, which is consistent with the small content of $\mathrm{OH}$.

\section{References}

[1] W. Bin, Z. Xinxin, L. Xin, J. ZeYi, and X. Yulei, "An inexact two-stage stochastic risk-aversion model for integrated energy system management in Beijing-Tianjin-Hebei, China," Journal of Renewable and Sustainable Energy, vol. 9, p. 045902 (19 pp.), 07/ 2017.

[2] X. Hu, "Experiment and mechanism study on the effect of coal ash on the capture of Alkali metals in Zhundong coal," in ASME 2017 Power Conference Joint with ICOPE 2017, POWER 2017-ICOPE 2017, collocated with the ASME 2017 11th International Conference on Energy Sustainability, the ASME 2017 15th International Conference on Fuel Cell Science, Engineering and Technology, and the ASME 2017 Nuclear Forum, June 26, 2017 - June 30, 2017, Charlotte, NC, United states, 2017, p. Advanced Energy Systems Division; Nuclear Engineering Division; Power Division; Solar Energy Division.

[3] S. Guoliang, Q. Xiaobin, S. Weijian, Y. Shaobo, L. Qinggang, and W. Nowak, "Slagging behaviors of high alkali Zhundong coal during circulating fluidized bed gasification," Fuel, vol. 186, pp. 140-9, 12/15 2016.

[4] D. Yongbo, W. Chang'an, L. Qiang, D. Lei, and C. Defu, "Influence of sodium on deactivation and regeneration of SCR catalyst during utilization of Zhundong coals," Asia-Pacific Journal of Chemical Engineering, vol. 11, pp. 973-80, $11 / 2016$.

[5] Y. Han, N. J. Yu, J. Dai, and G. B. Cai, "Application of conditioned level-set method to OH-PLIF image processing of typical molecule diffusion flames," 2015 2nd International Conference on Information Science and Control Engineering Icisce 2015, pp. 137-142, 2015.

[6] P.-H. Qiu, Y. Zhao, X.-Y. Chen, J.-J. Xu, Y.-W. Du, L.-X. Fang, et al., "Effects of alkali and alkaline earth metallic species on pyrolysis characteristics and kinetics of Zhundong coal," Ranliao Huaxue Xuebao/Journal of Fuel Chemistry and Technology, vol. 42, pp. 1178-1189, 2014.

[7] S. Zhong, Y. He, K. Qiu, Z. Wang, B. Li, J. Liu, et al., "Measurement of alkali content in Zhundong coal by LIBS method," Qiangjiguang Yu Lizishu/High Power Laser and Particle Beams, vol. 27, 2015.

[8] Y. Deguchi, M. Noda, M. Murata, M. Sota, and M. Inada, "Application of Laser Induced Fluorescence to Practical Combustion Fields," Journal of Neuropathology \& Experimental Neurology, vol. 68, pp. 736-46, 2009.

[9] J. E. Dec and P. L. Kelly-Zion, "The effects of injection timing and diluent addition on late-combustion soot burnout in a di diesel engine based on simultaneous 2-D imaging of OH and soot," in SAE 2000 World Congress, March 6, 2000 - March 9, 2000, Detroit, MI, United states, 2000.

[10] C. T. Johansen, C. D. McRae, P. M. Danehy, E. C. A. Gallo, L. M. L. Cantu, G. Magnotti, et al., "OH PLIF visualization of the UVa supersonic combustion experiment: configuration A," Journal of Visualization, vol. 17, pp. 131-41, 05/ 2014.

[11] K. K. Venkatesan, G. B. King, N. M. Laurendeau, M. W. Renfro, and B. Bohm, "Spatial and temporal characteristics of $\mathrm{OH}$ in turbulent opposed-jet double flames," Flow, Turbulence and Combustion, vol. 83, pp. 131-52, $07 / 2009$.

[12] Yang Fan, Zhu Guangming, Ding Changfu, "Slagging Analysis and Retrofit of a Refractory Belt in the 600MW W-flame Bolier,"Journal of Chinese Society of Power Engineering,vol.36, pp.421-427,2016(in Chinese).

[13] Shi Jinming, Xiang Jun, Hu Song. Change of coal structure during washing process, "CIESC Journal, vol. 61, pp. 3220-3227, 2010. (in Chinese). 